\title{
Intention and permissibility
}

\author{
Amir Saemi \\ University of California, Santa Barbara
}

\begin{abstract}
There are two kinds of view in the literature concerning the relevance of intention to permissibility. While subjectivism assumes that an agent acts permissibly if he or she believes that their conduct is necessary for a moral purpose, for objectivism the de facto presence of an objective reason to justify one's deeds is what matters. Recently, Scanlon and Hanser have defended a moderate version of objectivism and subjectivism, respectively. Although I have a degree of sympathy toward both views, I will argue that the truth lies somewhere in between. The view that I suggest in this paper hopefully occupies a space between subjectivism and objectivism and can accommodate the intuitions that neither of those views can account for.
\end{abstract}

KEYWORDS. Intention, permissibility, ethics, action theory.

\section{INTRODUCTION ${ }^{1}$}

Tn his "Competing Theories of Justification: Deeds v. Reasons," Paul Robinson distinguishes between two kinds of moral justification. On the one hand, there is a subjective theory of justification according to which an agent is justified if he or she believes that the conduct is necessary for a moral purpose. On the other hand, there is an objective theory of justification according to which the de facto presence of an objective reason to justify one's deeds is what matters. With regard to the relevance of intention to permissibility, subjectivists maintain the principle of double effect, while objectivists, among them Judith Jarvis Thomson as an eloquent proponent, deny it. The subjective and objective theories of justification presented by Robinson, however, seem to be too extreme. 
In his new book entitled Moral Dimensions, Permissibility, Meaning, Blame and other papers (e.g. Scanlon 2002, 2000) Thomas Scanlon defends a moderate objective view, while Matthew Hanser (2005) defends a moderate subjective view. Although the moderate objective and subjective views seem to be more plausible than the extreme positions, there are intuitions in favour of the subjective theory that moderate objective theory cannot accommodate, and, conversely, there are moral intuitions in favour of the moderate objective theory that the moderate subjective theory cannot accommodate. I hope to occupy a space between the moderate objective and subjective theory that can accommodate both kinds of intuitions.

\section{BACKGROUND}

\section{A. Intentional actions}

According to Anscombe, in order to analyze the concept of intention, we have to give an account of what is an intentional action. Anscombe accounts for intentional action as follows:

\section{Intentional action thesis}

$\mathrm{X}$ is intentionally $\Phi^{\prime}$ 'ing iff $\mathrm{X}$ is $\Phi$ 'ing \& in response to the question "Why are you $\Phi$ 'ing?" - where "why?" has relevant special senses - X can give an answer.

Thus, if the agent has an answer to the "why?" question, his or her action is intentional. On the other hand, there are cases in which the agent rejects the "why" question. If the agent rejects the "why?" question, his or her action is not intentional. Anscombe enumerates the rejection cases:

[R1] I didn't know I did

[R2] I know I was doing only because I observed it

[R3] It was involuntary

[R4] I was startled (a mental cause made me to do it) 
Given [R2] is a rejection of the "why?" question, the following thesis can be derived concerning intentional actions (see Falvey 2000):

\section{Knowledge thesis}

An agent's knowledge of his or her own intentional action is not based on observation.

Moreover, Anscombe gives an account of appropriate answers to the "why?" question, maintaining that it has relevant sense if the answer falls under one of the following categories:

[A1] Answers stating backward-looking motives (i.e. answers mention past history with ideas of good and evil)

[A2] Answers stating motives in general (e.g. curiosity, friendship, greed...)

[A3] Answers stating further intention with which one acts

[A4] Simple normal responses (e.g. he asked me)

[A5] Answers stating something like "for no particular reason"

[A6] Answers providing a response by expressing a wider description

These answers can usually be considered as an agent's intention in his or her action.

In part two of his new book (2008), Michael Thompson demonstrates the very important role of the progressive in analyzing the notion of intentional action. Anscombe demonstrated that an action can be described using a variety of different descriptions and Thompson adds that "every verb phrase with which Anscombe and Davidson illustrate the concept "description of action" expresses a kind of thing, a kind of event... that is intuitively continuous and divisible, that takes time, and that can be interrupted; the phrases themselves thus typically admit the "continuous tenses or the progressive"." $(2008,106)$. Hence, an action is an event or process and can be described by using the progressive. More importantly, Thompson argues that one can use the progressive to rationalize intentional actions. In his words, 
"It is... only because we are to start with the kind of thing of which you can say something like "She's doing A because she's doing B" that we can be or become the sort of which you might say "She's doing A because she wants to do B". It is possible to imagine a form of life and thought in which the latter, sophisticated form is simply unknown. Among such agents, all of the work of straightforward rationalization is effected by means of the rationalization connective combined only with the categories of ordinary event consciousness" $(2008,92)$.

Thompson's formulation of intentional action is a sort of reverse of Anscombe's, although consistent with it. According to Anscombe's formulation, an intentional action must admit a certain sort of explanation or ground while according to Thompson's account, "an intentional action is itself a certain sort of account or ground - an explanans, not an explanandum (though perhaps it is that too)" (2008, 112, note 10). So, Thompson's account of intentional actions is something like:

$\mathrm{X}$ is intentionally $\Phi$ 'ing iff $\exists \psi \mathrm{X}$ is intentionally $\psi^{\prime}$ ing because $\mathrm{X}$ is Ф'ing

As far as my purpose in this paper is concerned, however, I am not interested in Thompson's formulation. I am more interested, rather, in Anscombe's formulation where the action in question appears as an explanandum. More precisely, I am interested in the case in which an intentional action is rationalized (or explained) by using a wider description in the progressive form ([A6] above). As previously noted, Anscombe enumerates six different relevant answers to the 'why?' question. [A6] is the case I am interested in. Thompson's account does not logically imply that the other five categories are reducible to [A6] (although some of them, like [A1], [A3] and perhaps [A4], would presumably be reducible). In light of his discussion, however, one can arguably claim that most actions are processes unfolding within a wider process. In other words, most actions can be explained by giving a wider description in the progressive form. The actions described by the widest description, however, cannot be so explained. The actions under the 
widest description sometimes need no further explanation. In Thompson's words, they are practices or forms of life. The widest process cannot be explained instrumentally. At most, as Anscombe says, it sometimes needs only to be seen in a certain light by indicating general motives. The conclusion that we can draw from this section is that most actions can be rationalized by using a wider description thereof in a progressive form.

\section{B. Adverbial versus adjectival}

Hanser (2005) makes a distinction between adverbial and adjectival accounts of permissibility and I am inclined to follow his distinction.

One can distinguish between an act-type and an act-token. Consider the act of 'drinking a cup of coffee'. 'Drinking-a-cup-of-coffee' is an acttype that can be done by anyone, but my drinking a cup of coffee is a particular, unrepeatable instantiation of that type. Correspondingly, permissibility judgments can be divided into two categories: Adjectival permissibility judgments (e.g. $\Phi^{\prime}$ 'ing is impermissible) concern act types: they specify things agents may or may not do. Adverbial permissibility judgments (e.g., X acted impermissibly in $\Phi$ 'ing), by contrast, concern particular tokens of actions. Hence, although 'driving-to-the-store' is normally permissible, I might act impermissibly in driving to the store with my neighbour's car without his or her permission.

Having distinguished the two accounts of permissibility, allow me to make following points: Firstly, act-tokens are adverbially (im)permissible no matter how they are described. In other words, the truth-value of the permissibility judgment is independent of the way the action is described. If I am driving to the store with my neighbour's car without his or her permission, I am acting impermissibly. Using the adverbial account of permissibility, it is incorrect to say that I acted permissibly in driving the car, but impermissibly in driving my neighbour's car without his or her permission. In Hanser's words, “'adverbial permissibility judgments enable us to express overall verdicts about actions. They enable us to say not just 
whether an agent acts permissibly insofar as his action instantiates this or that type, but whether he acts permissibly full stop" $(2005,445)$.

Secondly, many philosophers who defend the irrelevance of intention to permissibility conflate the adjectival account of permissibility with the adverbial. It seems fairly plausible that permissibility in the adjectival sense is irrelevant to intention. In other words, the permissibility of an act-type is irrelevant to intention. In my view, there can be certain rules and considerations, or in Scanlon's terms "guides for deliberation", by which we can determine the permissibility of act-types. For example, killing, all other things being equal, is impermissible (in the adjectival sense). However, the issue is whether or not intention is relevant to the permissibility of acttokens (i.e. in the adverbial sense). For example, did I act impermissibly in killing an innocent person given that I am a tactical bomber? I will discuss this issue in some detail in the paragraphs that follow.

III. The MOderate SUbjective VIEW VERSUS THE MODERATE ObjeCtive VIEW

According to Hanser, "an agent acts morally permissibly if and only if his action embodies a practical inference whose premises' justifying force, if any, is not successfully undermined or defeated by any moral considerations" $(2005,448)$. Extreme subjectivism supposes that one acts permissibly if one believes that there is a good reason to $\Phi$. Hanser's theory (or the moderate subjective theory) differs from the extreme subjective theory in supposing that the mere fact that one believes there is a good reason to $\Phi$ is not sufficient to justify one's actions. Rather, there must in fact be a good reason and one must adopt that reason to be justified in one's action. On the other hand, according to the extreme objective theories (among them J.J. Thomson's), the mere fact that there is in fact a good reason to $\Phi$ is sufficient to justify one's $\Phi$ 'ing. The moderate objective view differs from the extreme objective view in supposing that the mere fact that there is in fact a good reason for $\Phi$ 'ing is not sufficient to justify 
one's $\Phi$ 'ing. Rather, there must be in fact a good reason to $\Phi$ and that reason must be reasonably accessible.

Scanlon (who supports a moderate objective view) distinguishes between two kinds of moral principle: "guides for deliberation" and "standards for criticism". The former is relevant and the latter is irrelevant to permissibility. The "standards for criticism" are the criteria used to examine whether someone is morally at fault or blameworthy and are thus beyond the scope of this paper. The "guides for deliberation" concern the question: "May one do X?" They identify the considerations that make it permissible or impermissible to do X. Therefore, Scanlon would argue that one acts permissibly if one acts in accordance with the "guides for deliberation". Scanlon argues against the relevance of intention to permissibility along the following lines:

(S1) The permissibility of an action is determined by guides for deliberation

(S2) Guides for deliberation in general are independent of one's intention $--$

So (S3) One's intention is irrelevant to the permissibility of one's action

(S1) seems to be true if it concerns permissibility in the adjectival sense. (S2) seems to be plausible too. So, the argument seems to be good if permissibility is understood in the adjectival sense. While Hanser would agree with this argument, he would also say that intention is relevant to permissibility in the adverbial sense. To prove the irrelevance of intention to permissibility in the adverbial sense, Scanlon would add the following premise:

(S4) One acts impermissibly iff there is a description of one's action which is impermissible ${ }^{2}$ (in the adjectival sense)

In other words, (S4) states that permissibility in the adverbial sense is reducible to permissibility in the adjectival sense without appealing to the concept of intention. 
Adding (S4) to (S3), one can conclude that one's intention is irrelevant to impermissibility in the adverbial sense. In other words, according to (S3), permissibility judgments in the adjectival sense are irrelevant to intention, and according to (S4), regardless of one's intention, the permissibility of one's action in the adverbial sense is reducible to permissibility judgments in the adjectival sense. Therefore, the permissibility of one's action in the adverbial sense is irrelevant to one's intention.

Hanser mentions (S4) in his paper and sets it aside without further argument. (S4), however, seems to be false. To determine the reason for this, let us first consider the following proposed thesis:

(*) X acts impermissibly in $\Phi$ 'ing iff there is a description $d$ of $\Phi$ such that $d$ is impermissible \& $\Phi$ under $d$ is intentional.

A more precise version of $(*)$ would be:

(**) X acts impermissibly in $\Phi^{\prime}$ ing iff [there is a description $d$ of $\Phi$ such that $d$ is pro tanto impermissible $\& \Phi$ under $d$ is intentional \& there is no description $d^{\prime}$ of $\Phi$ such that $\Phi$ under $d^{\prime}$ is intentional \& $d^{\prime}$ can justify $d$ (See footnote 2)

Since the consideration of cases involving pro tanto impermissibility introduces further complexities, I will avoid such considerations here for the sake of simplicity. So, I set (**) aside in this section and use the simpler from $\left(^{*}\right)$. Comparing $\left(^{*}\right)$ and $(\mathrm{S} 4)$, we can see that $(\mathrm{S} 4)$, to be different from $(*)$, implies the following premise: ${ }^{3}$

(S5) It is possible that [one acts impermissibly $\&$ there is a description of one's action which is impermissible \& there is no impermissible description of one's action under which the action is intentional]

I think (S5) is false. I will argue that if there is a description of one's action which is impermissible, then one can find a description of action which is impermissible and under which the action is intentional. 
Consider the act-type $d$ (e.g. closing-the-door). An agent's action does not just instantiate $d$, he or she instantiates $d$ in a particular way. While an agent is usually unable to fully conceptualize his or her way of acting, the manner in which he or she acts remains an inseparable part of his or her action that should be considered in the question of permissibility. Using Hanser's example, although it is permissible to close a door to protect a baby from the cold weather, one acts impermissibly if one closes the door quite forcefully (forcefully enough to awaken the baby). So, it seems that the agent acts impermissibly in his or her action involving closing-the-doorforcefully. In other words, although closing-the-door is permissible, there is another description of the action namely closing-the-door-forcefully which is impermissible and the action under this description can be intentional.

In general, as we observed in (S4), if one acts impermissibly then there is a description of one action say $\mathrm{F}-X^{\prime} / y$ which is impermissible. But, is the agent's $\mathrm{F}$ ing-X'ly always intentional under this description? Scanlon answers no to this question. His examples are $\mathrm{F}$ 'ing-recklessly, or F 'ing-negligently which are impermissible and can be done unintentionally. For example, causing-harm-negligently is impermissible and can be done unintentionally.

Even in such cases, however, the agent would agree that he or she F 'ed-in-this-way intentionally. For example, the agent may reject that the claim that he or she intentionally closed-the-door-forcefully, nevertheless he or she would agree that they intentionally closed-the-door-in-this-way, and there are certain considerations and guides according to which one may not closed-the-door-in-this-way when a baby is sleep. The important point here is that closing-the-door-in-this-way represents an impermissible act-type and the agent's action is intentional under this description. So, the point is not whether or not his or her closing-the-door-forcefully or his or her F ing-X'ly (or his or her $\mathbf{F}$ ing-negligently) is intentional, but whether there is at least one impermissible description of the agent's action under which the action is intentional. I would be inclined to answer in the affirmative. 
If one's causing harm is the result of a freak accident there cannot be any impermissible description under which the action is intentional. However, I have a strong intuition that causing harm through a freak accident is not impermissible. What distinguishes between causing harm through a freak accident and other similar yet impermissible cases (e.g. harming negligently) is that, if causing harm is not the result of a freak accident, one could normally have prevented it. So, if one's causing harm is not the result of a freak accident, one could have acted (or could act) in a good manner. The impermissibility of one's acting is thus the result of one's bad manner of acting, e.g. acting-in-this-way in circumstance C. I conclude that, excluding the case of freak accidents, the impermissibility of one's action in pseudo-unintentional actions (i.e. negligence or recklessness) is due to one's acting-badly intentionally (e.g. one's acting-inthis-way), and so (S5) is false.

I think that $\left(^{*}\right)$ can place the question of the relevance of intention to permissibility in a new light. To demonstrate this, let us first examine the intuitions against the moderate objective and subjective views.

\section{IntUitions against the MODERATE subjective AND OBjeCtive VIEWS}

\section{Against the moderate subjective view}

According to the moderate subjective view, one acts impermissibly if one does a permissible action for a bad reason. So, the moderate subjective theory is committed to the claim that any trivial permissible action can be done impermissibly. Consider, for example, the voodoo case: People who believe in voodoo think that by sticking pins in a doll they are thereby bringing about the agonizing death of their enemy. According to the moderate subjective view, an agent would act impermissibly if he or she were to stick pins in a doll with the intention of thereby killing (or harming) someone ${ }^{4}$. Nevertheless, it sounds strange to claim that a harmless act of 
sticking pins in a doll is impermissible. It is more striking if we consider that, according to the moderate subjective theory, an agent would act impermissibly were he or she to perform any trivial or harmless or even beneficial action with bad intention. A special case that has the same logic is the case presented by J.J. Thomson in which, according to the moderate subjective view, a beneficial action could be done impermissibly. J.J. Thomson's story is about a man named Alfred whose wife is dying, and whose death he wishes to hasten. Alfred buys a stuff-thought-to-be-poison and gives it to his wife with the intention of thereby hastening her death. Unbeknown to him, the stuff is the only cure for his wife. J.J. Thomson's intuition is that Alfred acted permissibly if he gave the stuff to his wife.

When a judgment involves an act-type which is absolutely adjectivally impermissible, the judgments resulting from the moderate subjective view are the same as the judgments resulting from the moderate objective view. Both views imply that if an act-type is adjectivally absolutely impermissible, then any token that instantiates that type would be normally adverbially impermissible. So, both views have the same sort of opinion on cases involving adjectivally absolutely impermissible actions. Their genuine disagreement is on the cases that involve either no adjectivally impermissible action or a pro tanto adjectivally impermissible action that is justified by another adjectivally permissible act-type. My objection here particularly concerns the former case, i.e. the case in which there is no impermissible act-type, although the action can be done impermissibly depending on the intention with which one acts. Indeed, I am inclined to believe that such a claim leads to the counter-intuitive result that any harmless or beneficial action can be done impermissibly.

\section{Against the moderate objective view}

As we have seen, the moderate subjective view cannot accommodate the case in which an agent performs a harmless action with a bad intention. On the other hand, the moderate objective view cannot accommodate cases where the action itself is vicious but ultimately turns out to have good effects. 
Let us consider Robinson's example of an agent who maliciously burns his neighbour's cornfield, although it turns out that the burning serves as a firebreak to an oncoming forest fire about which he did not know. The burning ends up saving the nearby town. My intuition says that the agent acted impermissibly in this case and a freak accident cannot justify him in viciously burning his neighbour's cornfield. A similar case would be Robinson's example about viciously beating an attacker-thought-to-be-a-jogger.

While the cases in question appear similar to the voodoo case and the case of the cure-thought-to-be-poison, I am convinced they are different: the field burning case includes the performance of a malicious deed, but in the voodoo case nothing harmful is done. Neither the moderate subjective view nor the moderate objective view can explain this difference, while the view I will defend below has this capacity. If I am right in believing that there is an asymmetry between these two cases, and if my view can offer a plausible explanation for this asymmetry, then the asymmetry in question can serve as evidence for the truth of my view.

Another case in which the objective seems to go against our intuition is the act of terror/tactical bombing. A terror bomber drops bombs on civilians in order to terrorize the enemy population and cause enemy leaders to sue for peace. A tactical bomber, by contrast, does not use civilians as a means of promoting the end of a war. He or she drops the bomb on a legitimate military target such as a factory, although the death of a number of civilians is ultimately foreseeable. We suppose that the number of people killed in the both cases is equal. Furthermore, while we can suppose that the same factory will be destroyed in the terror bomber case, the latter does not care about the destruction of the factory and is unaware of the military advantages (if any) yielded by the destruction of the factory. The (moderate) objective view does not make any distinction between terror thus described and tactical bombing. According to the (moderate) objective view, either both cases are justified or neither is justified. Intuitively, however, there is a difference between these two cases, a difference that cannot be explained by the objective view. 
As a concluding point concerning the moderate objective view, I would argue that it sometimes gives rise to counter-intuitive results in the cases where the vicious action takes time and has several parts. Consider Scanlon's example in which an agent buys poison from a store to kill his wife. Scanlon's opinion on this case is that the act of buying the poison is not done impermissibly because the poison is under the control of the agent who intends to carry out the murder and he can still decide not to use it to kill. Scanlon thinks that the man will have done something wrong only when the action is finished. I find this conclusion counterintuitive. Our actions do not have well-defined borders nor is it clear in Scanlon's view at which point the act of killing begins. Moreover, in light of Thompson's work we observe that an action must be regarded as a process-in-progress. As such, it seems that the act of buying the poison is part of the process-in-progress of killing.

\section{THE PROpOSED VIEW}

I believe the following principles (which are elaborated versions of $(*)$ ) can explain the relationship between intention and permissibility:

$\left.{ }^{* *}\right) \mathrm{X}$ acts impermissibly (adverbially) in $\Phi$ 'ing iff [there is a description $d$ of $\Phi$ such that $d$ is (pro tanto)(adjectivally) impermissible and $\Phi$ under $d$ is intentional \& there is no description $d$ ' such that $\Phi$ under $d$ is intentional and $d^{\prime}$ can justify $d$ ]

$(* * *) \mathrm{X}$ acts permissibly in $\Phi^{\prime}$ ing iff $\{$ [there is no description $d$ of $\Phi$ such that $d$ is impermissible and $\Phi$ under $d$ is intentional] or [there is a description $d$ of $\Phi$ such that $d$ is pro tanto impermissible and $\Phi$ under $d$ is intentional \& there is another description $d$ ' such that $\Phi$ under $d$ ' is intentional and $d^{\prime}$ can justify $\left.d\right]$ \}

$(* *)$ and $(* * *)$ illustrate a two-factor view. On the one hand, objective external features determine the (im)permissibility (in the adjectival sense) of an 
act-type (or a process-type) identified by a description. On the other hand, whether an action is intentional under the description in question determines the (im)permissibility of the action (token) in the adverbial sense.

The cases referred to above can be explained on the basis of (**) and $\left({ }^{* *}\right)$. With regard to the act of burning-one's-neighbour's-cornfield, a person acts impermissibly in doing so because there is an (adjectivally) impermissible description of the action, namely burning-one's-neighbour's-cornfield under which the action is intentional. Although there is another description of the action, namely saving-the-town, which might justify the impermissible description, the action under the description of saving-the-town is not intentional. Hence the agent acts impermissibly in viciously burning his or her neighbour's field.

The case of attacker-thought-to-be-a-jogger exhibits the same logic. A person acts impermissibly in beating an attacker-thought-to-be-a-jogger because the justifying act-type has not been done unintentionally.

As I observed earlier, it seems to me that there is an asymmetry between the aforementioned cases involving false beliefs and other cases involving false beliefs, e.g. the voodoo case or the case of the curethought-to-be-poison. Intuitively speaking, in the field-burning case a malicious action has been done and the action under the impermissible description is intentional. At the same time, however, it seems to me that in the case of the cure-thought-to-be-poison nothing harmful has happened and the description of killing-one's-wife is not a true description of the man's action. Before proceeding to cases involving these kinds of false beliefs, let us first examine another case somewhat similar to the field-burning case, namely the case of terror/tactical bombing.

I would argue with respect to the case of terror/tactical bombing that a person acts permissibly in tactical bombing because even if a pro tanto impermissible description of the action were available, namely killing-theinnocents, under which the action is intentional, the action would be intentional under another description, namely destroying-a-legitimate-militarytarget, which can justify the pro tanto impermissible description. A person 
acts impermissibly in terror bombing, however, because there is an impermissible description of the action, namely killing-the-innocents, under which the action is intentional, and there is no description under which the action is intentional that can justify the impermissibility of killing. Two points should be made about this case. Firstly, it is a matter of dispute whether or not the act of tactical bombing is intentional under the description of killing-the-innocents. I take it for granted that one can assume that the action is intentional under the description of killing-the-innocents. ${ }^{5}$ Second, for the sake of argument, I suppose that killing a number of innocents as a side effect of a good military mission can be morally justified. The truth of this view, however, is beyond the scope of this paper.

Let us return to the cure-thought-to-be-poison and voodoo cases, in both of which I believe a person acts permissibly.

Prima facie, it seems that my view entails that these two acts cannot be done permissibly because the action in the voodoo case is intentional under an impermissible description namely killing-the-enemy, and the action in the cure-thought-to-be-poison is intentional under the impermissible description of killing-his-wife. I will argue, however, that the descriptions killing-the-enemy and killing-his-wife are not true descriptions of the actions in question.

Falvey argues that intentional action is possible only against a background of reliance on information obtained through observation ${ }^{6}$. Suppose I want to make an Irish Breakfast tea. I take down a tin marked 'Darjeeling' from the shelf and proceed to spoon some of its contents into the pot. Suppose I simply wasn't paying sufficient attention to what I was doing for a moment. When I finally realise that I am spooning Darjeeling into the pot, there are two possibilities for me: 1) If I am willing and able to pour out the contents of the pot and replace it with the right stuff, I need not to withdraw my judgment that I am making Irish Breakfast tea and I can go on making Irish tea. I had started making Darjeeling tea for a few moments - there was an event in progress of Darjeeling tea making, which would have been completed if I had not 
noticed the mistake. Thus my judgment "oops, I'm making Darjeeling!" expresses knowledge obtained through observation of something I was doing, albeit unintentionally. 2) Upon seeing what I have done I might say, "well, I guess I'm making Darjeeling". Here I am no longer willing or able to make Irish tea. My judgment would express a change of mind. I withdraw my claim to be making Irish tea (I was making Irish tea unintentionally for a while), change my mind and go on making Darjeeling.

The same situation can be observed in the case of the man killing his wife. When the man realizes that he was in fact saving his wife, he may say "oops, I'm saving my wife". Here he realized that his action, in fact, was an act of unintentionally saving. From this point, either he continues killing his wife by another means, or he refrains from killing. In either case, the description of his action during the period of giving the curethought-to-be-poison was saving-his-wife unintentionally and not killinghis-wife.

Falvey writes: "A judgement about what I am doing is subject to revision if I become aware of something that gives me reason to think that I cannot do it" (2000, 29). Falvey's words lead to the following principle:

If I think that I am $\Phi$ 'ing \& I cannot $\Phi$, then I was not $\Phi$ 'ing

Judgment about intentional actions requires a background of reliability. In the absence of such a background, the above principle demonstrates that the intentional action thesis and knowledge thesis do not always give us the right answers. The principle explains why the man was not killing his wife, and thus the description of killing-his-wife is not a true description of his action.

The same would appear to be the case in the voodoo example. Hence, killing-the-enemy is not a true description of the action in this case. At most, the description of the action would be killing-the-enemy-by-sticking-pins-in-a-doll, and this would be a particular kind of killing, which is not of the same sort of killing that is impermissible. 
Similarly, the act of buying poison from a store to kill one's wife seems to be impermissible (in both the adverbial and adjectival sense). In fact, the act of killing one's wife is an action-in-progress that is impermissible. I would thus argue that the different parts of this ongoing process, including the act of buying poison from the store, are also impermissible ${ }^{7}$ (adverbially and adjectivally).

The difference between the case of buying poison to kill one's wife and the case of the cure-thought-to-be-poison is that in the latter case, one's action deviates from the process of killing and falls under another category. The agent acts impermissibly, however, as soon as he revises his action so that he proceeds with the process of killing his wife.

I have argued that external factors determine the permissibility of an act-type. Whether or not an act-token is impermissible (in the adverbial sense) depends on whether or not the act-token instantiating that act-type is intentional under the description that identifies the impermissible acttype. There is a well-known argument presented by J.J. Thomson, however, against the relevance of intention to permissibility in any sense. I will briefly address the said argument here in order to demonstrate that it does not undermine the view supported by the present contribution.

J.J. Thomson's argument runs as follows:

It is a very odd idea... that a person's intentions play a role in fixing what he may or may not do. What I have in mind comes out as follows. Suppose a pilot comes to us with a request for advice: "See, we're at war with a villainous country called Bad, and my superiors have ordered me to drop some bombs at Placetown in Bad. Now there's a munitions factory at Placetown, but there's a children's hospital there too. Is it permissible for me to drop the bombs?" And suppose we make the following reply: "Well, it all depends on what your intentions would be in dropping the bombs. If you would be intending to destroy the munitions factory and thereby win the war, merely foreseeing, though not intending, the deaths of the children, then yes, you may drop the bombs. On the other hand, if you would be intending to destroy the children and thereby terrorize the Bads and thereby win the war, merely foreseeing, though not intending, the destruction of 
the munitions factory, then no, you may not drop the bombs." What a queer performance this would be! Can anyone really think that the pilot should decide whether he may drop the bombs by looking inward for the intention with which he would be dropping them if he dropped them? $(1991,293)$

Let us examine J. J. Thomson's argument on the basis of Hanser's reconstruction thereof, which offers a response similar to my own.

(JT1) It would generally be absurd for a deliberating agent, concerned to act permissibly, to reflect, as part of his decision-making process, upon the intentions with which he would be acting.

So, (JT2) Whether an agent acts permissibly cannot generally depend upon the intentions with which he acts.

(JT1) is false. As we observed in the first section of this contribution, in the majority of cases, the intention with which an agent acts can be determined by a wider description of the agent's action. In fact, when an agent is performing an intentional action, he or she is involved in an ongoing incomplete process. So, (JT1) means that it would generally be absurd for a deliberating agent to reflect, as part of his or her decision-making process, upon the action he or she is doing, or the ongoing process he or she is completing. This interpretation demonstrates that (JT1) is false. A tactical bomber is involved in an act of attacking-a-legitimate-target and this very description of the action, under which the action is intentional, makes the action permissible (adverbially). In other words, there is an act-type, namely attacking-a-legitimate-target, which is supposed to justify the act-type killing-innocent-people. There is nothing odd in the idea that the bomber may reflect upon 1) whether the process (/action) he is involved in is part of the process (/act) of bombing-a-legitimate-target (after all, permissibility is the property of actions and bombing-a-legitimate-target is the very action the agent is doing); 2) and whether bombing-a-legitimate-target has enough justificatory force against the pro tanto 
impermissible description of killing. ${ }^{8}$ A negative answer to either of these questions can make the bomber's action impermissible (adverbially).

J.J. Thomson's concern, however, is that the agent need never direct his attention inward to be confident of the permissibility of his action. This concern is out of place in the present view, however, because it is the external features that make the act of tactical bombing permissible.

As I indicated in the introduction, I prefer to occupy a space between the moderate objective view (Scanlon's view) and the moderate subjective view (Hanser's view) since I have a degree of sympathy towards both.

I can agree with Scanlon in his basic idea that deliberative guides make the act-types permissible. Moreover, Scanlon endorses the idea that the meaning of an action is determined by the intention of the agent and the meaning of the action is relevant to its permissibility (I take the meaning of action to be equivalent to the description of the action, but Scanlon means something different by 'meaning of an action'). Scanlon, however, is not whole-heartedly prepared to endorse this idea and this is why he cannot see that terror bombing and tactical bombing have two different meanings and thus differ in permissibility.

Akin to my own view, Hanser offers a two-factor theory. According to him, there must be an objective reason for an act to be permissible and the agent must adopt that reason. Since he does not endorse the idea that the kind of reason that is relevant to permissibility is embodied in a description of the action, however, he cannot see why there is nothing impermissible in voodoo-like cases.

\section{WORKS CITED}

Anscombe, Gertrude E.M. 1957. Intention, New York: Cornell University Press. Falvey, Kevin. 2000. "Knowledge in Intention.” Philosophical Studies, 99: 21-44. Hanser, Matthew. 2005. "Permissibility and Practical inference." Ethics 115: 443-470. Robinson, Paul. 1996. "Competing Theories of Justification: Deeds v. Reasons." In Harm and Culpability. Ed. Andrew P. Simester and A.T. Smith, 45-70. Oxford: Clarendon. 
Scanlon, Thomas M. 2008. Moral Dimensions, Permissibility, Meaning, Blame, Cambridge, MA: Belknap.

Scanlon, Thomas M. 2002. Moral Assessment and the Agent's Point of View. Unpublished manuscript, Harvard University.

Scanlon, Thomas M, 2000. "Intention and Permissibility I." Proceedings of the Aristotle Society, 74: 301-317.

Thompson, Michael. 2008. Life and Action, Elementary Structures of Practice and Practical Thought, Cambridge, MA: Harvard University Press.

Thomson, Judith J. 1991. "Self-Defense." Philosophy and Public Affairs 20: 283-310.

\section{NOTES}

1. I would like to thank Matthew Hanser and the journal's referees for their comments. Moreover, I would like to thank the copy editor of the journal for his help in improving the language of the paper.

2. Strictly speaking, it is not the descriptions that are (im)permissible, but the action-types that are (im)permissible (in the adjectival sense). In other words, strictly speaking, (S4) should be revised as follows:

(S4') One acts impermissibly iff there is an act-type which is adjectivally impermissible, and one's action instantiates that act-type.

However, an act-type, say killing, can be identified in relation to descriptions (e.g. class of actions that can be properly described as killing). Hence, we can tolerantly say that descriptions (identifying act-types) are (im)permissible in the adjectival sense.

3. Here is the reason: (S4) and $(*)$ have the same antecedent and different consequents. Since (S4) is not logically equivalent to $\left(^{*}\right)$, it is possible for both the antecedent and consequent of (S4) to be true and the consequent of $(*)$ to be false. (S5) express this possibility.

4. It is worth mentioning that the moderate subjective view (as well as the moderate objective view) is purely formal. To draw the results of such views, I assume some uncontroversial substantive thesis about what is bad and good. In the case in question, for example, I implicitly assumed that that a morally impermissible end is incapable of justifying anything

5. Consider the case of tactical bombing. The pilot knows that he is going to kill a certain number of civilians at the instant of pushing the button. He has even some relevant answer to the 'why' question. So, I am strongly inclined to take the act of killing civilians as an intentional action. This is a reason why I have no sympathy with the principle of double effect. The distinction between intended and foreseeable results is untenable. I think that the action that leads to a foreseeable result is always, or at least in most cases, an intentional action. I find this claim in accordance with both the intentional action thesis and the knowledge thesis, although it remains a matter of dispute.

6. I am greatly influenced by Falvey (Falvey 2000) here. The example and the manner of presenting the example are also his. 
7. However, it remains a matter of dispute. The fact that one cannot draw a sharp line between different parts of an action together with the fact that the amount of the contribution of each part towards achieving the final end of the process cannot be clearly determined support my view.

8. As stated, I suppose that attacking a legitimate military target can justify killing a certain number of civilians, but an agent who is concerned to act permissibly may want to re-evaluate this assumption. 